\title{
BLAS DE OTERO Y LA CENSURA ESPAÑOLA DESDE 1949 HASTA LA TRANSICIÓN POLÍTICA. SEGUNDA PARTE: DE QUE TRATA DE ESPAÑA (1964) A TODOS MIS SONETOS (1977)
}

\author{
LuCía MONTEJo GuRRUCHAGA \\ Facultad de Filología. UNED \\ Madrid
}

En los años sesenta, después de dos décadas de aislamiento y el consecuente empobrecimiento cultural, España empieza a vivir un proceso de apertura hacia posiciones de neocapitalismo homologado. Con la llegada del turismo y las primeras inversiones de capital extranjero, comienza a superarse la economía de autarquía y a desarrollarse las bases de una economía típica de mercado. Si durante los años cuarenta y cincuenta la dirección ideológica y administrativa del nuevo Estado se apoyaba en la alianza entre falange y democracia cristiana, en los años sesenta el régimen franquista se asentará sobre el influjo de los tecnócratas del Opus Dei.

Hay varios estudios y con enfoques distintos sobre las transformaciones que experimentó la censura en las cuatro décadas en las que sus normas estuvieron vigentes. Si en los primeros años de la dictadura sus principios se impusieron con severidad - y siempre arbitrariamente-, sus efectos fueron - comparativamente- algo más flexibles durante la década siguiente. Ruiz Giménez, ministro de Educación desde 1951 a 1956, intentó una tímida liberalización en el ámbito cultural, pronto abortada por las fuerzas ultraconservadoras, encabezadas por el clero, que desencadenaron una reacción que produjo un retroceso irreversible. La llegada de Fraga Iribarne, que ocupó el Ministerio de Información y Turismo desde 1962 hasta 1969 significó - para algunos - un cierto grado de tolerancia, pero la supuestamente liberal Ley de Prensa promulgada a bombo y platillo en 1966 para sustituir a la que seguía vigente desde 1938, ni simplificó los trámites ni los aceleró ni allanó obstáculos. La censura previa, que había sido hasta entonces obligatoria, se transformó en voluntaria - así lo recogían los impresos que había que formalizar-, lo que significó que las autoridades se reservaban la última palabra. Nadie se atrevía a acudir al dic- 
tamen definitivo y los autores seguían sometiendo sus obras a consulta previa ${ }^{1}$. La Ley Fraga trajo algunas consecuencias beneficiosas, como la emergencia pública de discrepancias políticas e ideológicas con el Gobierno $\mathrm{u}$ otros órganos de poder, lo que produjo un pluralismo en la prensa, que se convirtió en foro privilegiado de discusión pública dada la falta de cauces de participación en la vida política. Tuvo también graves efectos negativos, como la frecuencia con la que aplicaron las sanciones y las situaciones límite que produjo.

Habrá que esperar hasta los primeros años setenta para vislumbrar una nueva apertura -así denominada por las instancias oficiales- que será muy desigual. Sánchez Bella, el sucesor de Fraga, que ocupará el cargo hasta 1973, endurecerá la política de censura y los tres ministros que desde junio de 1973 le sucedieron -Fernando Liñán, Pío Cabanillas y León Herrera- se mantuvieron en el cargo por tan breve espacio que solo este hecho fue indicio claro de que la dictadura estaba viviendo sus últimos e inestables días.

La liberalización se notó antes en el terreno económico que en el desarrollo científico y cultural, y esta contradicción entre la apertura y el despegue económico y las prácticas retrógradas en el ámbito cultural, se convertiría en uno de los principales problemas del franquismo tardío. Hasta el fin de la dictadura nadie estuvo a salvo de la censura.

En estas difíciles condiciones históricas muchos poetas de distintos grupos y generaciones, y con una gran pluralidad de manifestaciones crean, desde finales de los años cuarenta hasta mediados de los sesenta, una poesía de denuncia y testimonio, una poesía comprometida, inmersa en un momento histórico concreto a la que la tradición crítica ha endosado la etiqueta de poesía social. Con su actitud insurgente contra el marco político establecido y la consideración de la responsabilidad, legitimidad y poder histórico de la palabra, ofrecerán una alternativa de lenguaje y una propuesta de vanguardia ideológica mediante la que filtrarán mensajes que trasluzcan la realidad social. Blas de Otero será uno de sus representantes más relevantes, genuinos e innovadores. El tema social, que dominó el panorama poético español en esos años, se inicia en el poeta vasco con su libro Pido la paz y la palabra en 1955 y se extenderá a En castellano y Que trata de España. El poeta al defender que poesía y temática social no

1 Para una detallada información sobre la organización de este mecanismo de control entre 1936 y 1976, y la eficacia e influencia que alcanzó, remito a Manuel L. ABELlÁN, Censura y creación literaria en España (1939-1976), Barcelona, Península, 1980. R. GUBERN, La censura. Función política y ordenamiento jurídico bajo el franquismo (1936-1975), Barcelona, Península, 1981. Hans-Jörg NEUSCHÄFER, Adiós a la España eterna. La dialéctica de la censura. Novela, teatro y cine bajo el franquismo, Barcelona, Antropos, 1994. J. SinOVA, La censura de prensa durante el franquismo, Madrid, Espasa Calpe, 1989. 
pueden ser conceptos antagónicos, no sólo huirá de las vías de deslizamiento de otros poetas sociales hacia territorios no poéticos, sino que creará una de las escrituras más auténticas del momento. El peculiar contrapeso que consigue en el poema entre discurso referencial y técnicas de transgresión y desplazamiento de sentido, será también un arma —en bastantes ocasiones - para salvar la barrera de la censura.

En el artículo que dediqué al comportamiento del órgano censor en los diez años que van desde la publicación en 1949 del primer libro de Blas de Otero Ángel fieramente humano, hasta 1959 en que le deniegan la autorización para publicar En castellano, puse de manifiesto la feroz persecución que sufrió su $\mathrm{obra}^{2}$. Cuando presenta su primer libro al premio Adonais en 1949, el jurado lo excluye alegando motivos de heterodoxia religiosa; uno de sus poemas, junto a otras causas, es el detonante que provocó el fin de la revista Espadaña, se repiten los problemas con la edición de Ancia y sufre un auténtico calvario con En castellano. El regateo, las mutilaciones y tachaduras de versos primero, poemas enteros después, dieron paso más tarde a drásticas resoluciones, a decisiones irreversibles.

Todos estos impedimentos no le hicieron desistir en el empeño de publicar en su país, y aunque los quince años a los que se circunscriben estas páginas,que van desde 1960 hasta el final de la dictadura son arduos y difíciles para el poeta, son también intensos y fructíferos. Sus poemas se recogerán en las antologías más significativas, tanto en las que se publican en España como en el extranjero ${ }^{3}$, se hacen muchas ediciones de sus libros, sus poemas se traducen a los más diversos idiomas y la prensa, tanto nacional como extranjera, le dedica la atención que merece por su calidad estética y se hace eco de los avatares que sufren sus obras. Obtiene premios importantes y el reconocimiento, por tanto, de crítica y público. Entre 1960 y 1964 realiza largos viajes, primero a la Unión Soviética

2 En la primera parte de este artículo titulado «Blas de Otero y la censura española desde 1949 hasta la transición política. Primera parte: de Ángel fieramente humano a En castellano», RLit, LX, 120, 1998, 491-513, puse de manifiesto el momento histórico, político y literario en el que se editan los libros del poeta vasco que se publican entre 1949 y 1959. Analicé los expedientes de censura y demás documentación generada por Ángel fieramente humano, Redoble de conciencia, Ancia, Pido la paz y la palabra y En castellano, y su repercusión; estudié asimismo los expedientes abiertos a raíz de segundas ediciones y los incoados por distintas solicitudes de importación de algunas de estas obras.

3 Pueden verse en: el estudio de Manuel MANTERo, «Quince antologías poéticas (años 60)» Celacanto, Revista de Literatura, Huelva, 3-4, primavera 1991, 76-91, y los dos volúmenes de Emili BAYO, La poesía española en sus antologías (1939-1980), Lérida, Universidad de Lérida, 1994, en los que ofrece una reflexión sobre el fenómeno de las antologías poéticas -en su vertiente histórica y tipológica- y la lista de poetas más ampliamente representados: Blas de Otero está en el grupo de cabeza. 
y a China —invitado por la Sociedad Internacional de Autores-, después a Cuba.

En marzo de 1962 Blas de Otero entrega a la editorial RM de Barcelona el manuscrito de su libro Ardua patria para ser publicado en su colección «Poesía contemporánea española». En su nombre lo presentará a censura Ramón Juliá López el 21 de marzo y se le asignará el núm. de expediente 1550-62. Está archivado en el AGA (Archivo General de la Administración en Alcalá de Henares) y es la primera vez que los dictámenes se hacen públicos. El original del libro lo componen 30 poemas escritos a máquina. El censor - F-28 en esta ocasión - tras anotar que no tiene antecedentes, emite el 26 de marzo el siguiente parco informe:

«Nada que objetar a este libro de versos de Blas de Otero, en el que se muestra bastante más comedido que en otros suyos. PUEDE AUTORIZARSE».

Se trata de un manuscrito en el que el poeta había reunido siete poemas pertenecientes a Pido la paz y la palabra, que había guardado por no poner en peligro la edición de Torrelavega ${ }^{4}, 12$ de En castellano entre autocensurados y mutilados del ejemplar cuya publicación le había sido denegada, y 11 que correspondían a Ardua patria.

La autorización - sin regateos, tachaduras ni retrasos- se cursa el mismo día 26, lo que les confirma que es el momento oportuno después de más de una década de problemas. Acaba de recibir el premio Fastenrath de la Real Academia por Ancia ${ }^{5}$ y el momento es para él inmejorable.

Blas de Otero tenía casi terminado un nuevo libro y mediante la estrategia de la Adición ${ }^{6}$ enviará el 7 de abril, 70 poemas para añadir a Ardua patria. Pasarán por distintas manos - procedimiento empleado cuando se trataba de un autor relevante y «muy fichado»- y se van sucediendo los informes de los censores antes de acordar la resolución. El primero señala el 9 de abril que deben suprimirse los poemas «Diego Velázquez» ${ }^{7}$, «Pa-

4 Blas DE OTERo, Pido la paz y la palabra ,Torrelavega, Cantalapiedra, 1955.

5 El jurado, reunido el 25 de febrero, estuvo formado por Gerardo Diego, Sánchez Cantón y Vicente Aleixandre, quien propuso el libro de Blas de Otero. Gerardo Diego «alegó ciertos escrúpulos morales. Había en el libro - advirtió- una fe vacilante y ciertas libertades de palabra al tocar temas sexuales..., alegó incluso un artículo del Reglamento de la Academia, que habla del deber de los académicos en velar por las buenas costumbres... Pero Vicente insistió en la superior calidad poética del libro de Otero, y logró convencer a Sánchez Cantón anulando los supuestos escrúpulos morales y religiosos de Gerardo.» Véase al respecto el libro de José Luis CANO, Los cuadernos de Velintonia, Barcelona, Seix Barral, 1986, 153.

6 Esta estrategia le había dado buenos resultados cuando la utilizó para la publicación de Ancia. Puede verse el proceso en la primera parte de este artículo.

7 Había sido publicado junto a «In memoriam», Insula, XVII, 184, marzo 1962, 2 , sin contratiempos. 
rábola de doble filo» y «Teruel-Yonne». A partir de aquí el expediente se detiene cinco meses. Se propagan y multiplican las huelgas en el Norte, se producen las detenciones de sus amigos de Bilbao (Ormazábal, Ibarrola, etc.) y arrecian las protestas de los intelectuales contra el órgano censor. En una entrevista que acuerdan con Fraga Iribarne, recién nombrado ministro de Información, el 27 de julio de 1962, a la que acuden -entre otros- Torrente Ballester, López Rubio, Alfonso Sastre, Claudio de la Torre, Carlos Muñiz, Juan García Hortelano, López Salinas, Ricardo Doménech, José García Nieto y José Luis Cano, le piden, además de la necesaria liberalización de la censura, que se termine con el anonimato de los censores todopoderosos ${ }^{8}$.

La sección de inspección no justifica el retraso en la resolución del expediente de Ardua patria; las demoras en los fallos eran práctica común. El segundo censor anota en el informe que «dentro de la conocida significación político-social de Blas de Otero no se puede autorizar el poema «¿Cuándo será que España», y un tercero fallará cuatro meses más tarde -el 11 de febrero de 1963 - con estas palabras: «Conocida la tendencia de Blas de Otero, la superioridad debe revisar los poemas «Zurbarán 1957» y «Ah de la vida» ${ }^{9}$. Este último, encabezado por una cita de Quevedo, tenía pocas posibilidades de pasar inadvertido pues recoge vocablos considerados subversivos y el poeta rinde con él homenaje a compañeros con los que comparte la defensa de la libertad. Estos son los versos:

$$
\begin{aligned}
& \text { «No hablo por hablar. Escribo } \\
& \text { hablando, sencillamente: } \\
& \text { como en un cantar de amigo. } \\
& \text { Nazim, Marcos, Lina Odena, } \\
& \text { Nina van Zandt, compañeros } \\
& \text { en la libertad más bella. }
\end{aligned}
$$

8 Sobre las reiteradas quejas de los intelectuales contra este órgano de control pueden verse las pruebas que aporta José Luis CANO en Los cuadernos de Velintonia, op. cit., 157. La mejor muestra del anonimato bajo el que se escondían los censores son los expedientes. Entre ellos - lectores en el argot del Ministerio- había distintas categorías: jefe de lectorado, lector especialista, lector eclesiástico, lector fijo o eventual. Había entre ellos personas de gran prestigio, catedráticos, cargos políticos adscritos al régimen de Franco, escritores, y había otros muchos - personal fijo o eventual- de escasa y deficiente formación cultural, como pronto ponen en evidencia los informes. Se identificaban por un número y firmaban los dictámenes - por lo general- con una firma ilegible, sobre todo si eran negativos. Cumplieron con rigor estas normas en los primeros años - algunos las obedecieron siempre-, pero después de descifrar un buen número de informes, leer y releer docenas de expedientes, muchos de estos garabatos se le van haciendo familiares al estudioso y van destapando a su signatario.

9 Las resoluciones de los censores están escritas a máquina en algunas ocasiones para que sus autores no puedan ser identificados, aunque no es el comportamiento habitual, y la firma es un garabato indescifrable. 
La libertad del que forja un pueblo libre: Miguel Hernández cavó la aurora.

¡Ah de la vida! Preguntas a tientas: «el mar», «el campo»...

Las olas se han vuelto mudas.

Veintidós años... Decidme cómo es un árbol. Quién silba arriba en el aire libre.

Quién me recuerda. Quién llama desde el fondo de la mina. Espaciosa y triste España.

La libertad por el suelo. Tú la levantas, la apoyas en el hombro del obrero.

El olivo y las espigas te dan la mano, se pasan, brisa a brisa, la consigna.

Como en un cantar de amigo escribo lo que me dictan la fábrica y el olivo.»

Dos días antes de que se fallara el tercer informe, el 9 de febrero, el editor solicita la autorización para cambiar el título de Ardua patria ${ }^{10}$ por Que trata de España y ampliar, de nuevo, la obra. Se le concede y el 5 de abril remite las «nuevas poesías que se añadirán al citado libro así como dedicatorias, índice, colofón y bibliografía». Siguen los forcejeos con el jefe de la sección de Orientación Bibliográfica. Blas de Otero suprime poemas completos, mutila y altera versos según las indicaciones de los censores, pero es tanta la documentación que se acumula y tantos los cambios producidos en el año largo de disputas, regateos y altercados, que la Sección correspondiente del Ministerio escribe a la editorial RM el 11 de mayo de 1963 comunicándole que «para proceder a resolver su petición sobre el cambio de título de la obra Ardua patria de Blas de Otero, deberá presentar en esta Sección el original completo que haya de publicar definitivamente». El manuscrito que entrega, y que está archivado en el AGA junto a los dictámenes, lo envían el 14 de junio; contiene 83 poemas y están numerados a mano por el propio autor.

10 Sin embargo este título ha dejado su huella. En el libro de Sergio VILLAR, Arte y libertad, Barcelona, Fontanella, 1964, 256, se recogen los títulos de los libros del poeta vasco, y entre ellos aparece Ardua patria. 
Blas de Otero solía mostrar algunos de sus poemas en publicaciones periódicas relevantes para sondear el comportamiento de la censura antes de incluirlos en libro e Ínsula sería en ocasiones la elegida. La revista ofreció un homenaje a Rafael Alberti en el número del mes de mayo y Carlos Robles Piquer, director general de Información en aquellos momentos, llamó a José Luis Cano - secretario de Ínsula - cuando el número se presentó a censura, para exigirle la supresión del artículo de Aquilino Duque, y de los poemas de Blas de Otero y Ángel Crespo que pretendía publicar ${ }^{11}$. Al mismo tiempo le reprocha que en el número de abril hubiese publicado unos poemas de Otero, de temas españoles ${ }^{12}$, que provocaron un fuerte ataque del diario Pueblo contra Blas de Otero y contra Ínsula ${ }^{13}$.

11 Ínsula, 198, mayo 1963. Consecuentemente no fueron publicados ni el artículo ni los poemas. Me informa Sabina de la Cruz que el poema de Blas de Otero que pretendían incluir en el homenaje a Alberti es el titulado «Historia de una palabra», que tuvo que esperar varios años, hasta 1970. En junio de ese año, el Colegio de Arquitectos de Cataluña y Baleares organizó una exposición homenaje al poeta gaditano. El comisario de la muestra - J. Corredor Mateos- escribe a Blas de Otero solicitándole permiso para incluir el poema en el catálogo y rogándole que suprima un verso que puede acarrearles problemas con la censura. Se trata del siguiente, que pongo en cursiva para destacarlo: (...) «Las casas apagan las enjalbegadas fachadas./El alba/ un poco deteriorada, un sí no es estropeada, cuarteada,/ pisada por botas yankis, con un nudo corredizo en la garganta.» En su lugar, al dar el poeta el consentimiento, apareció una larga línea de puntos suspensivos, práctica común de autocensura y que él —como otros creadores- ya había tenido que utilizar en otras ocasiones. El verso fue repuesto al incluirlo entre los nueve poemas que recogió con el título «Escrito para», Papeles de Son Armadans, 216, marzo 1974, 252-264 y posteriormente en su antología Poesía con nombres, Madrid, Alianza, 1977, 88.

12 Se trata de Ínsula, 197, abril 1963. En la página 3 aparecieron a toda plana diez poemas de Blas de Otero. A pie de página se apunta: «(Del libro de inmediata aparición Que trata de España. Editorial RM, Barcelona.)». Entre ellos se incluyen algunos de los que estaban siendo mutilados, que serán denegados y no podrán ser incluidos en la edición de RM. Se trata de «Antedía», "Año muerto, año nuevo» y "Ah de la vida» que habían padecido reiterados ataques.

13 Y aún más. Algunos periódicos y revistas arremetieron contra Ínsula por lo que consideraron un apoyo a escritores de ideología comunista. Ya en enero de 1963 ABC había iniciado una campaña para demostrar que todos los homenajes que se preparaban entonces en España eran de inspiración comunista. La Estafeta Literaria la acusó de servir «de albergue, de incubadora o de palanca para el totalitarismo comunista», y se hacía eco del Premio Omegna-Resistenza otorgado a Blas de Otero extrayendo únicamente estas líneas del artículo que le dedicó La Stampa el 29-IX-1963: « el jurado ha tenido presente que en la lucha contra el régimen franquista participan activamente intelectuales y poetas, en cuyo grupo Otero es la figura preeminente», salía en defensa de la libertad de expresión que - según ellos - practicaba el régimen con estas palabras: A Blas de Otero «nadie le exige que se retracte ni se confiese ni se autocritique... hace lo que quiere». Véase el artículo «Dialogamos de verdad con Ínsula», Estafeta Literaria, 277 ,octubre 26, 1963, 31 y 32. Me comunica Sabina de la Cruz que Blas de Otero, que vivía entonces en la casa familiar de Bilbao, trata de este asunto en cartas a José Luis Cano, a su traductora de italiano Elena Clementelli y a su traductor al francés Claude 
Las batallas planteadas hasta entonces no han servido de nada; después de más de un año de desencuentros hay que empezar de nuevo partiendo de cero. El 26 de junio, Javier Dietta, lector especialista ${ }^{14}$, emite el siguiente informe:

«Blas de Otero es un poeta exiliado. En los versos que acoge este volumen expone preocupacion o sus sentires sobre España, agarrandose a sus piedras, su historia, su clima. Muy unamunesco. Me parece que tienen bilis politica los poemas de las páginas $4,8,41,44,49,50,59,64$ y deberian suprimirse» ${ }^{15}$.

El día 15 de julio otro censor replica al anterior —práctica común- y llama la atención de la superioridad con las siguientes palabras:

«Se hace constar que todos los versos contenidos en este volumen fueron anteriormente presentados y aprobados, algunos después de haber suprimido el editor lo indicado por el lector. Únicamente el de la página 49 "No hablo por hablar. Escribo" estaba pendiente de resolución, después de indicadas las tachaduras que habían de hacerse en el. Sin desconocer la significación de Blas de Otero ni su íntima intención, puede aconsejarse la publicación de este libro tal como ahora se presenta».

El expediente contiene, además, otros documentos. Incluye una fotocopia de una reseña de la revista Ibérica ${ }^{16}$ titulada «Libertad de expresión», que dice:

«El gran poeta Blas de Otero ha escrito un nuevo libro titulado Que trata de España, que debía aparecer en la editorial RM de Barcelona. De pronto han

Couffon. Son del mes de junio de 1963 y poseen cierto aire entre el humor, la desesperación y la tristeza: «Vaya una situación tan «orgánica» - escribe a Cano-. Me hago cargo de tu disgusto y los trastornos para la revista. Lo del llamado «Pueblo» no lo conozco. ¿Podrías mandármelo? Aquí es difícil y aunque más o menos me basta con lo que me dices, sería mejor lo viese.» Y a Couffon: «Ahora debía aparecer en Barcelona mi nueva obra Que trata de España, si no salió ya es a causa de las condiciones que padecemos aquí. Todavía andan forcejeando unos últimos puntos en censura y no es seguro que pueda publicarse». Al comunicarle a Elena Clementelli esta misma información, la denomina «una noticia curiosa».

${ }_{14}$ Cuando se consideraba que un libro atacaba el sistema institucional implantado por el franquismo, sus principios ideológicos, la religión como institución y jerarquía, o atentaba contra la moral del implantado integrismo católico, abandonaba los cauces habituales y pasaba a un lector especialista.

15 Copio los informes tal y como figuran en el manuscrito original, sin añadir ni quitar una coma ni un acento. Estas líneas ponen en evidencia la escasa o nula formación de muchos miembros del órgano censor.

16 Ibérica, por la libertad, Nueva York, 78 , julio-agosto 1963, 8C. Esta interesante revista, editada por Victoria Kent desde Nueva York y subvencionada con la ayuda de simpatizantes americanos, fue un instrumento de denuncia de la falta de libertades en España. 
surgido dificultades, y la censura se opone a su aparición. Esa es la obra "liberal" de los Srs. Fraga, Cabanillas, Robles Piquer y Quílez, los cuatro responsables del Ministerio. Los poemas de Blas de Otero, algunos de los cuales son conocidos, pertenecen a lo más valioso de su obra poética y denuncian todos ellos la opresión que sufre España ${ }^{17}$ \%.

Contiene asimismo una carta del Subdirector General de Difusión - J. Benítez Lumbreras - con fecha 24 de septiembre de 1963, dirigida al Jefe de la Sección de Orientación Bibliográfica solicitándole información «sobre el estado en que se encuentra la publicación de este libro, a la mayor brevedad.»

El editor Ramón Juliá, en vista de que el expediente no se resuelve y el libro lleva parado más de año y medio, decide buscar la forma de activarlo $^{18}$ y convence al poeta para que suprima gran parte de los poemas mutilados. Adjuntan, por tanto, el 22 de octubre, un nuevo ejemplar de Que trata de España con algunas modificaciones. Introduce 25 poemas nuevos, y como no está dispuesto a plegarse, mantiene algunos de los íntegramente tachados y explícitamente prohibidos en el dictamen anterior, como «Heroica y sombría», «Impreso prisionero» o «Cuándo será que España». Adjuntan asimismo una lista con los títulos de los poemas que habían sido aprobados en el expediente 1550-62, es decir, en el primitivo de Ardua patria. Además, altera el orden de algunos poemas conflictivos esperando que en esta ocasión el manuscrito caiga en manos de un censor más benévolo o menos avisado.

Se le abre un nuevo expediente, el número 6000-63 y aunque la coordinación entre el cuerpo de censores dejaba mucho que desear, recayó - y seguramente no por casualidad - sobre Javier Dieta que reproduce, el 26 de octubre, casi con las mismas palabras que el anterior, este nuevo informe:

«Versos varios, muchos politicos. Otero es un «opositor». Creo que los versos que se indican, que hay que suprimir enteros, tienen bilis política. Se deben suprimir los siguientes:

\section{pág. 5: «El mar/ alrededor» 7: «Heroica y sombría» 18: «La vida»}

\footnotetext{
17 Los subrayados aparecen en la fotocopia. En 1963 Manuel Fraga Iribarne desempeñaba el cargo de Ministro de Información y Turismo, cartera que ocupó desde 1962 hasta 1969. Pío Cabanillas fue subsecretario del Ministerio durante el mismo periodo, y Robles Piquer - cuñado de Fraga - y Quílez fueron directores generales de Información.

18 No podemos olvidar que los editores solían expurgar de antemano lo que juzgaban censurable o sujeto a dudas y practicaban, en ocasiones, una censura previa a la oficial. Puede verse al respecto el libro del profesor Julio NEIRA, Blas de Otero. Correspondencia sobre la edición de Pido la paz y la palabra, Madrid, Hiperión, 1987.
} 


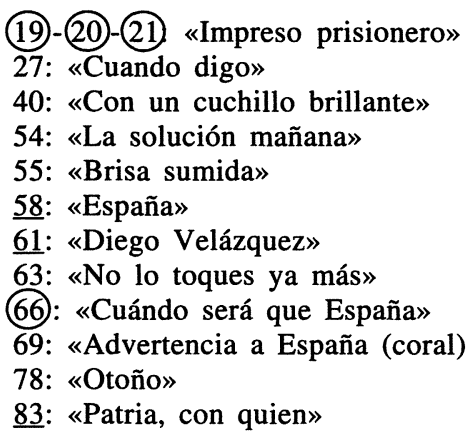

Los poemas subrayados o encerrados en un círculo tenían ya una larga tradición censoria ${ }^{19}$. «Heroica y sombría» aparece en el original íntegramente tachado en rojo. Este es el poema, escrito en cuartetas asonantadas:

\author{
«De haber nacido, haber \\ nacido en otro sitio; \\ por ejemplo, en Santiago \\ de Cuba mismo. \\ De haber nacido, haber \\ nacido en otra España; \\ sobre todo \\ la España de mañana. \\ De haber nacido, haber \\ nacido donde estoy; \\ en la España sombría \\ y heroica de hoy.»
}

Blas de Otero ha viajado por países en los que triunfa la revolución socialista, se ha entusiasmado con el compromiso de las masas y desea un cambio en su país, un mañana libre. Los encabalgamientos producen una sorpresa en la significación que los censores no pasaron por alto.

«Impreso prisionero» fue también tachado entero por el lápiz rojo que se detuvo en los versos doblemente censurables que aparecen así:

\author{
«He aquí \\ mis libros \\ (...) \\ hablo
}

19 Mantengo los círculos y subrayados tal y como figuran en los documentos originales. Con los subrayados pretenden llamar la atención de la superioridad, y los que están encerrados en un círculo eran los considerados más graves ideológicamente, los que atacaban el sistema implantado por el franquismo, sus instituciones o sus principios ideológicos. 


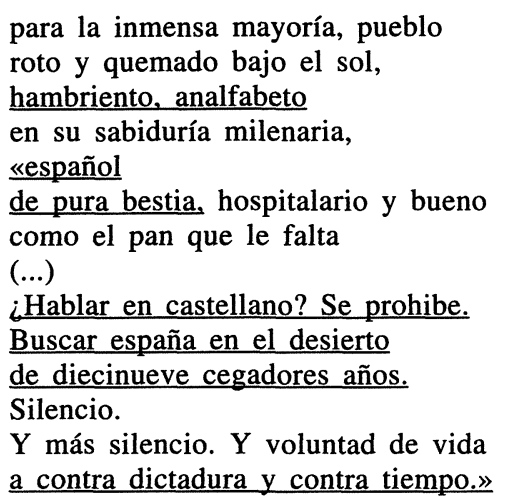

La dura realidad social de la España de los sesenta -analfabetismo, hambre, éxodo rural, emigración, represión-, una estructura social asfixiante y opresora, no son situaciones que puedan divulgarse. Si además alude a la guerra civil, al número de años que el país lleva soportando la dictadura, desciende a su situación personal - la severidad con la que le trata la censura por su notoriedad literaria y su posición política, hasta la prohibición de publicar En castellano ${ }^{20}$ en España- y se vale de una cita de César Vallejo ${ }^{21}$, con la que no sólo remoza el modelo, sino que ofrece una nueva visión de lo ya lexicalizado y tópico. El poema así se convierte en algo impublicable.

Ante tantos obstáculos interpuestos por la institución censoria el poeta ha podado y limado el manuscrito a cada encontronazo; las negociaciones - no todos los autores y editores tenían la posibilidad de encararse con la Administración - se han prolongado mucho más allá de lo previsto. Se apuran todos los recursos de ajuste y las consecuencias son muchas modificaciones significativas, muchos versos suprimidos, poemas mutilados y denegados.

Como ejemplo de delito político voy a servirme del poema «Brisa en las ruedas». Su título original, «Cuando venga Fidel se dice mucho» fue

20 Se editó con el título Parler clair, ed. bilingüe, traducido y prologado por Claude Couffon, París, Pierre Seghers, 1959. Enseguida será publicado por la Universidad Autónoma de México (1960) y casi al mismo tiempo en Buenos Aires por Losada. La cuarta edición la llevará a cabo también Losada en 1962, reuniendo en un solo volumen los cuatro libros de Blas de Otero (Ángel fieramente humano, Redoble de conciencia, Pido la paz y la palabra y En castellano) con el título general de Hacia la inmensa mayoría. En España sólo podrá publicarse con la llegada de la democracia (Barcelona, Lumen, 1977).

${ }^{21}$ Pertenece al poema «Salutación angélica» de Poemas humanos. Vallejo rompe la frase hecha «español de pura cepa», y mantiene la rima que enlaza la palabra intrusa y la omitida. Blas de Otero, siguiendo su estela, utilizará este procedimiento de idéntica manera. 
censurado y el poeta tuvo que sustituirlo en esta coyuntura. Pero, además, tuvo que reemplazar el nombre del político cubano, que aparecía en un verso; en su lugar aparece el absurdo nombre «quienquién» ${ }^{22}$.

La resolución se le remite a RM el 24 de marzo de 1964. Se concede la autorización para la publicación de Que trata de España de Blas de Otero con las modificaciones pactadas y después de eliminar más de un tercio de los poemas del libro. Blas de Otero acepta el sacrificio más duro para un escritor (la mutilación de su obra) en aras de que pueda publicarse en España y para los lectores españoles.

Han pasado dos años desde que se iniciaron los trámites y si el retraso constituía siempre una prueba de paciencia para el autor, la espera podía amenazar también la existencia del libro. Unos meses más tarde, la editorial Ruedo Ibérico llevará a cabo la edición completa de este libro en París ${ }^{23}$. Unos meses antes había publicado, también fuera de España, la antología Esto no es un libro en la que incluyó -además de una selección de poemas de sus libros anteriores- algunos denegados de En castellano y «los prohibidos por la censura en mi nuevo libro publicado este año en Barcelona bajo el título Que trata de España», como el propio poeta señala en la «Motivación» con la que abre el volumen ${ }^{24}$.

Estando Blas de Otero en París en 1964, es invitado a visitar Cuba para formar parte del jurado del premio de poesía «Casa de las Américas». Allí se llevará a cabo la edición completa de la trilogía Que trata de España ${ }^{25}$ y permanecerá, salvo viajes esporádicos, hasta abril de 1968 en que vuelve a España y fija su domicilio en Madrid. Trae dos libros inéditos, como le anuncia a Antonio Núñez en la entrevista que este le hace a los pocos días de su llegada, y le da cuenta también de algunas ediciones de sus libros llevadas a cabo en el extranjero y de otras en vía de publicación. Le recuerda también en esta entrevista la larga e intensa adversidad que han sufrido sus libros con estas palabras: «desde 1955 no he po-

22 Solo en esta ocasión se editará con este título; el poeta restituirá el original en la edición íntegra que se llevará a cabo unos meses después en París (Ruedo Ibérico, 1964).

23 En París, a finales de 1961 y en el ámbito de los exilados residentes fuera de España y en contacto con un grupo de intelectuales del «interior», se funda la editorial Ruedo Ibérico, que publica en español obras prohibidas por el régimen franquista y que, dado su éxito, entraban en España a cuentagotas de forma clandestina. Publicarían después la revista Cuadernos de Ruedo Ibérico, lugar de encuentro de los intelectuales de la oposición. La presentación del libro de Blas de Otero en la Librería Española de París, se convirtió en un acto masivo de rechazo a la dictadura franquista y de petición de libertades políticas.

${ }^{24}$ Blas DE OTERo, Esto no es un libro, Río Piedras, Universidad de Puerto Rico, 1963.

${ }_{25}$ Blas De OTERo, Que trata de España ,La Habana, ed. Nacional de Cultura, 1964. 1. ${ }^{a}$ parte: Libro I, Pido la paz y la palabra, Libro II, En castellano. 2. ${ }^{\mathrm{a}}$ parte: Libro III, Que trata de España. 
dido publicar un libro en España, ya que Ancia, que es del año 1958, no es más que una reedición de libros anteriores y la edición española de $Q u e$ trata de España está gravemente mutilada ${ }^{26}$. De Cuba trae su libro de prosas Historias fingidas y verdaderas y muchos de los poemas que constituirán Hojas de Madrid, inédito aún en parte, y a pesar de que llega a España gravemente enfermo y tiene que afrontar una grave operación, escribe y corrige incansablemente. En los últimos diez años, hasta la fecha de su muerte (29-VI-79), preparará distintas antologías ${ }^{27}$, revisará las reediciones de algunas de sus obras y seguirá escribiendo los poemas de Hojas de Madrid. En unos meses va a presentar a censura tres libros: la antología Expresión y reunión, Mientras - que como señala el autor en una nota que sirve de colofón al libro «casi todos los poemas son del libro inédito Hojas de Madrid»- e Historias fingidas y verdaderas.

En Expresión y reunión. A modo de antología (1941-1969), el primero de los que prepara recién llegado de Cuba, recoge una muestra de sus obras anteriores, pero presta especial atención a Que trata de España ofreciendo al lector un buen número de sus poemas en un intento de mitigar la grave mutilación que había padecido este libro en la edición española. Mostrará también algunas prosas de Historias fingidas y verdaderas y avanzará algunas composiciones de Hojas de Madrid. En septiembre de 1969 Jorge Cela Trulock en representación de la editorial Alfaguara presenta a censura el manuscrito.

A esta antología se le asignó el número de expediente 8843-69 y está también archivado en el AGA. Al día siguiente de su presentación el lector 12 emite el siguiente dictamen anónimo:

\begin{abstract}
«Antología de poemas de Blas de Otero, unos publicados y otros inéditos. Se nota en su poesía una tendencia cada vez mayor al machadismo y al poema en prosa; pero a medida que aquélla se politiza pierde calidad. Blas de Otero ya no es el poeta admirable que fue. Por supuesto, su poesía se hace más marxista cada vez. En sus últimos libros habla mucho de sus andanzas por Cuba, Rusia y la China comunista.

Por sus afirmaciones o insinuaciones promarxistas, antiespañolas o antimilitares, creo que deben ser suprimidos los poemas de las págs. $76, \underline{77}, \underline{83},(55) 104$, $105,118,151,(159) 162, \underline{201}, \underline{219}, \underline{222}, \underline{235}, \underline{238}$. No obstante, algunos de los poemas a suprimir figuran en libros impresos».
\end{abstract}

Nada ha cambiado después de dos décadas. Los censores siguen poniendo las mismas trabas y aplicando el mismo proceso de control anónimo e impenetrable. Siguen sin establecerse unas pautas concretas y la cen-

\footnotetext{
${ }^{26}$ Antonio NÚÑEZ, «Encuentro con Blas de Otero», Ínsula, XXIII, 259, junio 1968, 1 у 3.

27 Expresión y reunión. A modo de antología (1941-1969) ,Madrid, Alfaguara,1969; Verso y prosa, Madrid,Cátedra, 1974; Todos mis sonetos, Madrid, Turner, 1976; Poesía con nombres, Madrid, Alianza, 1977.
} 
sura continúa ejerciéndose con los mismos cánones durante las casi cuatro décadas de dictadura franquista. Pero algo sí ha cambiado: una sutil crítica seudo-literaria trata de enmascarar lo que no es más que pura censura política. El método hace fortuna y en el futuro es el que servirá para atacar a la poesía social durante muchos años.

El 27 de septiembre se le comunica la resolución a Alfaguara, que protesta enérgicamente porque algunos de estos poemas habían sido editados con anterioridad.

La denegación recae sobre tres poemas de En castellano, «Cartas y poemas a Nazim Hikmet», «No salgas, paloma, al campo» ${ }^{28}$ y «Tañer»; cuatro de Que trata de España, «Impreso prisionero», «Escrito con lluvia», «No hablo por hablar», «No lo toques ya más» y «1939-1942»; dos prosas de su libro -inédito entonces- Historias fingidas y verdaderas y dos poemas de Hojas de Madrid. De estos dos últimos libros Blas de Otero mostraba algunas composiciones por primera vez.

En castellano se había presentado en la sección de Inspección de Libros en julio de 1958. Fue denegada su publicación y devuelto el original al editor. El único rastro que dejó en el archivo fue la ficha de entrada ${ }^{29}$ y esto benefició al poeta porque, al menos, una selección de poemas de este libro pudo ser publicada en España en esta antología.

De los desestimados en Expresión y reunión que pertenecían a Que trata de España, solo uno de ellos - «No lo toques ya más»- había podido ser publicado en 1964 en la edición de Barcelona. Los demás, tenían una lar-

28 Este poema no tuvo ningún tropiezo cuando apareció por primera vez en España (Papeles de Son Armadans, 27 ,junio 1958) ni en 1960 en la antología de José María Castellet, Veinte años de poesía española 1939-1959, reeditada con el título de Un cuarto de siglo de poesía española, Barcelona, Seix Barral, 1965. Carlos Barral, en nombre de la editorial del mismo nombre, pidió la autorización para la publicación de esta antología, el 22 de marzo de 1960. El dictamen, que firma con letras mayúsculas el lector especialista José DE PABLO MUÑOZ —en contra de los hábitos censores-, se reduce a estas anodinas líneas: «La obra es una antología poética en dos partes: la primera tiene tres que destacan sobre las demás y son las tituladas:»Agonía del toro», "Adolescente en sombra» y «Gritando no morir». La segunda parte es una exposición histórica de la poesía desde 1898 hasta nuestros días. PUEDE AUTORIZARSE». La idea de esta antología parece que surgió - según confirma Barral (Los años sin excusa, Barcelona, Alianza, 1982, 175) - con ocasión del homenaje a Antonio Machado celebrado en Collioure en el vigésimo aniversario de su muerte, en el que coincidieron una serie de poetas. Llama la atención que esta antología poética, una de las más controvertidas que ha producido la literatura española, que tuvo como uno de sus propósitos dar a conocer a Barral, Gil de Biedma y J.A. Goytisolo arropados por poetas relevantes que legitimasen al grupo, y que recibió las más desmesuradas alabanzas y las valoraciones más negativas, no sufriera - teniendo además en cuenta el momento político- ni el más mínimo contratiempo con la censura. Castellet incluyó en ella doce poemas de Blas de Otero censurados o denegados en su mayoría. «No salgas, paloma, al campo» aparece en las dos ocasiones con numerosas variantes respecto al texto original que enmascaran la intención de crítica política. 
ga historia de problemas. Para el primero, «Impreso prisionero» - con una larga historia de denegaciones-, Blas de Otero propone algunas modificaciones en los versos más tachados, recogidas en el manuscrito archivado en el AGA junto al dictamen:

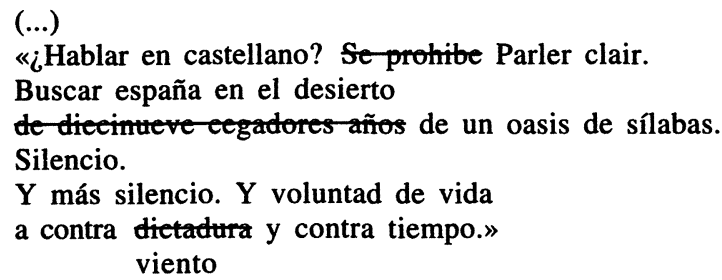

Debajo del poema el censor ha escrito: «Vale con las correcciones propuestas por el autor 24-10-69», y con estas modificaciones vio la luz en la edición de 1969.

Para el segundo, «Escrito con lluvia», el cambio fue menor en palabras pero no menos importante en el significado. Afectó al último verso:

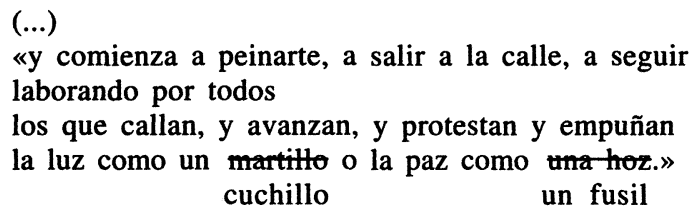

Una de las prosas de Historias fingidas y verdaderas, «Al azar», llamó también la atención del censor, que tachó y exigió la sustitución de las siguientes palabras, que enmarcó entre corchetes rojos:

«...De pronto, el cielo se vuelca en agua. El vagamundo se halla junto a la estatua de Céspedes, primer Presidente de la República en Armas. Y mientras cae la rápida lluvia, recuerda que allí mismo se alzaba hasta hace algunos años la de Fernando VII, [no el primer tirano ni el postrero, de la gloriosa España]» ${ }^{30}$.

La otra, «País» — título que cambiará por «Zaguán» cuando la publique en Historias fingidas y verdaderas- y los dos poemas pertenecientes

29 Todas las cuestiones sobre este libro pueden verse en mi artículo citado «Blas de Otero y la censura española desde 1949 hasta la transición política. Primera parte:».

30 Sabina de la Cruz señala en una nota a esta prosa en la 2. a edición de Historias fingidas y verdaderas, Madrid, Alianza, 1980, 93, que Blas de Otero —según su costumbre - sustituyó el final de este párrafo con una frase que hiciera ostensible la sustitución: «la de Fernando VII, eso dicen, tendré que consultar». Con esta sustitución apareció en la $1^{\text {a }}$ edición (Madrid, Alfaguara, 1970). 
a Hojas de Madrid titulados «El arco de triunfo» $\mathrm{y}$ «Cuento» fueron íntegramente censurados. En la edición de 1981 - siguiendo los deseos del poeta - se restituirán las palabras primitivas en las composiciones autocensuradas ${ }^{31}$.

La tarjeta para la autorización de la antología se remite a Alfaguara el 2-12-69.

Unos meses después, el 27 de julio de 1970, Julio Antonio Gómez en representación de la editorial Javalambre de Zaragoza, para su colección Fuendetodos ${ }^{32}$, solicita en el Ministerio de Información y Turismo, Dirección General de Cultura Popular y Espectáculos, la autorización para la publicación del libro Mientras de Blas de Otero. Está formado por poemas escritos desde su vuelta de Cuba en abril de 1968, encabezados por epígrafes procedentes de Historias fingidas y verdaderas, aún inédito en aquella fecha. En ellos el poeta reflexiona sobre la muerte que presiente cerca y acepta lúcida y serenamente el devenir, medita sobre el camino vital y creativo recorrido, sobre el amor, la revolución cubana -incluyendo expresiones y palabras propias del habla antillana-, la realidad sociopolítica española (censura, consumismo,...), y lo hace con el humor y la ironía de la que ha hecho gala en otras ocasiones. Los versículos de gran extensión, que imprimen al verso un compás lento, un ritmo retardado, el uso de un lenguaje incisivo y sintético, de progresiva condensación, y un apretado nudo de referencias, alusiones y símbolos bisémicos, acercan estos poemas a postulados y experimentaciones vanguardistas.

Se le asigna el expediente $n .^{\circ} 7749-70$ y pasa al lector 12 que emite, al día siguiente este informe:

\begin{abstract}
«Poemas inéditos de Blas de Otero. Libro, en general, inferior a otros del poeta, aunque contenga algunos poemas típicamente suyos y varios sonetos excelentes. Poemas a la Cuba de Fidel Castro, a la China de Mao, al Vietnam, a Moscú, La Habana, Bilbao y Madrid. Reminiscencias infantiles. Ironías políticas y literarias, «plagiando» versos de poetas famosos. Declaraciones de fe marxista. Odio-amor a Bilbao. Libro amargo y sardónico. Podría suprimirse el poema de las págs. 60-61, pero no me parece absolutamente necesario. AUTORIZADO.»
\end{abstract}

${ }^{31}$ Blas DE OTERO, Expresión y reunión, introducción y notas de Sabina de la Cruz, Madrid, Alianza, 1981. En esta segunda edición se incluirán los poemas censurados salvo uno, el titulado «El arco de triunfo», que sigue inédito.

32 Esta colección de poesía que se publicó entre los años 1969 y 1973, supuso un caso aparte por su concepción estética diferente y su indudable ambición. Su director, Julio Antonio Gómez, diseñó un original y delicado formato y una lujosa presentación. Los volúmenes -en tiradas cuantiosas, en general - se dedicaron a obras de poetas de prestigio; a libros de notable interés, de autores de nombre y obra consolidada, como Vicente Aleixandre, Luis Rosales y Blas de Otero, entre otros. El poeta vasco publicó, desde el principio, en las editoriales de más prestigio y reconocimiento, tanto en España como en el extranjero. 
Este censor alerta únicamente a la superioridad sobre uno de los veinticinco poemas que componen el volumen, algunos extensísimos. Se trata del titulado «Ergo sum», pero a continuación, en lugar de pasarlo a la firma del Jefe de Sección, como era preceptivo antes de pasar al Director General, alguien desvía el informe a un nuevo lector -el 24- que escribe el 17 de agosto, también a máquina para preservar el anonimato, esta resolución:

«Una serie de poemas, todos ellos en estilo y métrica libres, de temas muy diferentes y sin relación mutua, cuyo significado es dificil de comprender en muchos casos, entre los que aparecen algunos dedicados a España y otros a Cuba, expresandose siempre en tono amargo y resentido.

Del conjunto de poesias recogidas en el libro, se aconseja suprimir por tendenciosas o pro-comunistas, las acotadas en las pags. $26,40,56,57,60,61$, 78, 79, 92 y 93, asi como los versos subrayados en las pags. 68, 69 y 82 . El resto estimamos que ES AUTORIZABLE.»

Se ha producido un cambio radical. Este segundo dictamen afecta a seis de los veinticinco poemas que componen el volumen. Se trata de los titulados «Estas historias», «Compañía», «Ergo sum», «O nos salvamos todos», «Morir en Bilbao»y «Tania». Ambos censores coinciden en «Ergo sum» pues algunos asertos oterianos referentes a su ideología, a determinados aparatos represores, o a su creación no podían ser fácilmente digeribles por ellos. Veamos algunos versos:

(...) «A los 52 años sigo pensando lo mismo que Carlos Marx, (...) A los 52 años, escribo

y no escarmiento y me dedico exclusivamente a pasear, a leer, a trasladar maletas de un país a otro, y a conspirar,

(Esto lo digo para confundir a la policía.)

(...)

$\mathrm{Y}$ escribo como un autómata, corrijo como un robot, y publico lo que pienso (es un decir).

(...)

$\mathrm{Y}$ sigo pidiendo la paz y, de momento me la conceden en parte; y la palabra, y me mutilan la lengua.

$(\ldots) »$

La editorial Javalambre protesta contra esta resolución alegando que algunos de los poemas tachados acaban de hacerse públicos en la antología Expresión y reunión, y dos días después se les comunica, por escrito, que «se aconseja la supresión de los poemas de las págs. 56-57-92 y 93. Se trata de los titulados «Compañía» y «Tania». Después de comprobar que ambos han sido eliminados, se concederá la tarjeta de autorización para la publicación el 3-11-70. 
Por las mismas fechas estaba Blas de Otero pendiente de la resolución de Historias fingidas y verdaderas. El nueve de septiembre de este mismo año, Jorge Cela Trụlock en representación de la editorial Alfaguara había solicitado autorización para publicar el único libro en prosa del poeta vasco. ¿Se trata de prosa o de poesía? El mismo poeta duda al calificarlo y dice:

«el carácter de este libro no puedo definirlo estrictamente, tal vez se trata de relatos o ensayos condensados, acercándose otras veces más a cierto tipo de poema» ${ }^{33}$. «Estas historias entre la realidad y el ensueño son tan fingidas como verdaderas. Son historias porque en ellas se narra (o más bien se medita sobre) la propia vida. Pero también ensayos, porque el poeta trata en ellos de estética, política, viajes... En ocasiones semejan relatos, a veces descriptivos, otras históricos. Y todo ello con un estilo apretado, sometido a refinado control hasta presentar una engañosa sencillez y espontaneidad» ${ }^{34}$.

Se le adjudica el número de expediente $8887-70$ y el lector 8 escribe el siguiente informe unos días después:

«Blas de Otero se presenta en este libro ofreciendo una larga serie de reflexiones, consideraciones, descripciones, en torno a enunciados como la apuesta, la realidad, el demonio y sus cómplices, la plegadera, realizarse no es un juego de palabras, con acento en la í, el valle, está lloviendo de memoria, la calor, andar, solidaria isla, el azar, hacia las Azores, el segundo libro, etc. etc. PUEDE AUTORIZARSE».

En oficio de contestación de fecha 15-9-70, se le comunica al editor que no hay inconveniente para la publicación.

En esta primera edición de Historias fingidas y verdaderas, en la prosa titulada «Al azar», constatamos que el autor - dado el poco tiempo transcurrido - no se atreve a rescatar el texto original y mantiene la frase intrusa ${ }^{35}$.

Hay otros muchos expedientes de la obra oteriana en el AGA; corresponden a segundas y terceras ediciones tanto de libros como de antologías y a primeras ediciones de obras que en su momento tuvieron que ser publicadas fuera de España. Entre ellos está el núm. 7851-74 que corresponde a la 2." edición de País. Antología (1955-1970) de Blas de Otero, pre-

33 Conferencia que impartió en la Unión de Escritores y Artistas de Cuba, en La Habana, el 7 de marzo de 1967 a la que alude Sabina de la Cruz en la introducción a Historias fingidas y verdaderas, op. cit., 9.

34 Para una información detallada sobre la estructura de este libro y las características de la prosa se puede consultar, además de la ya mencionada introducción de Sabina de la Cruz, el volumen Blas de Otero. Poesía escogida, selección, introducción y notas de Sabina de la Cruz y Lucía Montejo, Barcelona, Vicens Vives, 1995.

35 Véase la nota 30. 
parada por José Luis Cano en 1971. El expediente de la primera edición, (la solicitud se cursó el 23 de enero de 1971 y se le asignó el núm. 73471) no está en el AGA. El único rastro que ha dejado es la ficha de entrada. El antólogo destacaba en País uno de los temas predilectos de la segunda etapa oteriana, el tema de España, al que años atrás Cano había dedicado otras antologías y estudios relevantes ${ }^{36}$. En el prólogo puntualiza que se trata de una selección de poemas en torno a este tema «en sus dos vertientes principales: de un lado, la preocupación por España -el ser, el destino, el drama de España-; de otro, el paisaje, el rostro vario y hermoso de la patria física». Cano pretendió incluir -guiado por el propio autor como manifiesta en el prólogo - algunos poemas inéditos aún en España de Que trata de España («Atardece», «Un lugar», «Historia de la Reconquista», «Cuando los trigos encañan», «Colorolor» y «Canción diecisiete»), la prosa de Historias fingidas y verdaderas, «País», denegada cuando se solicitó el permiso, y dos poemas de Hojas de Madrid ( «Francisco de Quevedo» y «Palabra permanente»), que no los había incluido en Expresión y reunión y no habían pasado aún la censura. Ignoro cuales son los motivos del rechazo de la primera edición, que José Luis Cano comunica a Aleixandre - provocando su indignación - con estas palabras: «la censura ha prohibido mi antología de Blas de Otero País que iba a publicar Plaza y Janés». Cuando se lo notifica a Blas de Otero, este le contesta: «iQue no liberalicen tanto, que vamos a caer en el libertinaje!» ${ }^{37}$. Sin embargo, la antología salió adelante después de unos meses. En la «Procedencia de los poemas», que se incluye al final de la antología, se recoge, como procedente de Hojas de Madrid, el poema «O nos salvamos todos (aparecido en 1970 en Mientras), que no está en esta antología. Seguramente fue eliminado por la censura por antiamericano. La segunda edición, solicitada en julio de 1974 no tuvo problemas acaso por lo avanzado de la fecha.

Están también en el Archivo General de la Administración el expediente de Verso y prosa ${ }^{38}$, antología preparada por el propio autor en 1973; el

36 Puede verse al respecto mi artículo «Las «limitaciones de expresión» en España durante las décadas cincuenta y sesenta: el ejemplo de dos antologías poéticas», Epos, Revista de Filología, UNED, XII, 1996, 277-295. En él estudio los comportamientos de la censura en dos antologías poéticas significativas del periodo: la Antología de la nueva poesía española (Madrid, Gredos, 1958) y El tema de España en la poesía española de posguerra (Madrid, Revista de Occidente, 1964). Ambas fueron preparadas y prologadas por José Luis CANO.

37 José Luis CANo, Los cuadernos de Velintonia, op. cit., 192.

38 A pesar de que la antología se publica casi a las puertas de la transición política, se vieron afectadas por el lápiz rojo de los censores el veinte por ciento de las composiciones. Se puede ver al respecto mi artículo «Blas de Otero y la poesía española: la antología Verso y prosa (1973)», monografía Volver a Blas de Otero, Zurgai, julio 1998, 38-41. 
que corresponde a Poesía con nombres de 1977; el de la primera edición completa en España de Que trata de España que publicó Visor en 1977, catorce años después de la edición gravemente cercenada de Barcelona, y el de Todos mis sonetos también de 1977, lo que denota que hasta esta fecha, a pesar de que la transición política había concluido y se había instaurado un régimen democrático dos años antes, hubo que continuar solicitando la autorización para la publicación ya que este órgano de control no se abolió hasta 1977.

El ceñido control que sufrió la obra oteriana, la demora indefinida -en ocasiones - del dictamen, ya que hasta la promulgación de la Ley de Prensa de 1966 no se fijó un plazo de contestación, el tira y afloja unas veces con los censores, otras - además - con los editores, a lo que había que añadir el consiguiente perjuicio económico, hubieran sido causas más que sobradas para minar su entereza. Sin embargo, y como hemos tenido la ocasión de comprobar, Blas de Otero desplegó durante más de dos décadas todo tipo de estrategias, presentó batalla con cada nuevo libro y encajó las represiones de la censura cuando lo creyó conveniente con un único propósito: publicar en su país, en su lengua y para sus compatriotas.

\section{OBRAS CITADAS}

ABELLÁN, Manuel, Censura y creación literaria en España (1939-1976), Barcelona, Península, 1988.

BARRAL, Carlos, Los años sin excusa, Barcelona, Alianza, 1982.

BAYO, Emili, La poesía española en sus antologías (1939-1980), Lérida, Universidad de Lérida, 1994.

CANo, José Luis, Los cuadernos de Velintonia, Barcelona, Seix Barral, 1986.

CAStellet, José María, Un cuarto de siglo de poesía española, Barcelona, Seix Barral, 1965.

Cruz, Sabina de la y Lucía Montejo Gurruchaga, Blas de Otero. Poesía escogida, Barcelona, Vicens Vives, 1995

GUBERN, R., La censura. Función política y ordenamiento jurídico bajo el franquismo (1936-1975), Barcelona, Península, 1981.

MANTERo, Manuel, Quince antologías poéticas (años 60), Celacanto, Revista de Literatura, Huelva, 3-4, primavera 1991, 76-91.

Montejo Gurruchaga, Lucía y Sabina de la Cruz, Blas de Otero. Poesía escogida, Barcelona, Vicens Vives, 1995.

-, «Las limitaciones de expresión en España durante las décadas cincuenta y sesenta: el ejemplo de dos antologías poéticas», Epos, Revista de Filología, UNED, XII, 1996, 277-295.

—, «Blas de Otero y la censura española: la antología Verso y prosa (1973)», monografía Volver a Blas de Otero, Zurgai, julio 1998, 38-41.

-, «Blas de Otero y la censura española desde 1949 hasta la transición política. Primera parte: de Ángel fieramente humano a En castellano», RLit, LX, 120, 1998, 491513. 
NEIRA, Julio, Blas de Otero. Correspondencia sobre la edición de "Pido la paz y la palabra", Madrid, Hiperión, 1987.

NEUSCHÄFER, Hans-Jörg, Adiós a la España eterna. La dialéctica de la censura. Novela, teatro y cine bajo el franquismo, Barcelona, Antropos, 1994.

NúÑEZ, Antonio, Encuentro con Blas de Otero, Ínsula, XXIII, 259, junio 1968.

OTERo, Blas de, Pido la paz y la palabra, Torrelavega, Cantalapiedra, 1955.

-, Historias fingidas y verdaderas, Madrid, Alfaguara, 1970.

-, Expresión y reunión. A modo de antología (1941-1969), Madrid, Alfaguara, 1969.

-, Mientras, Zaragoza, Javalambre, 1970.

SINOVA, J., La censura de prensa durante el franquismo, Madrid, Espasa Calpe, 1989.

VILAR, Sergio, Arte y libertad, Barcelona, Fontanella, 1964. 